
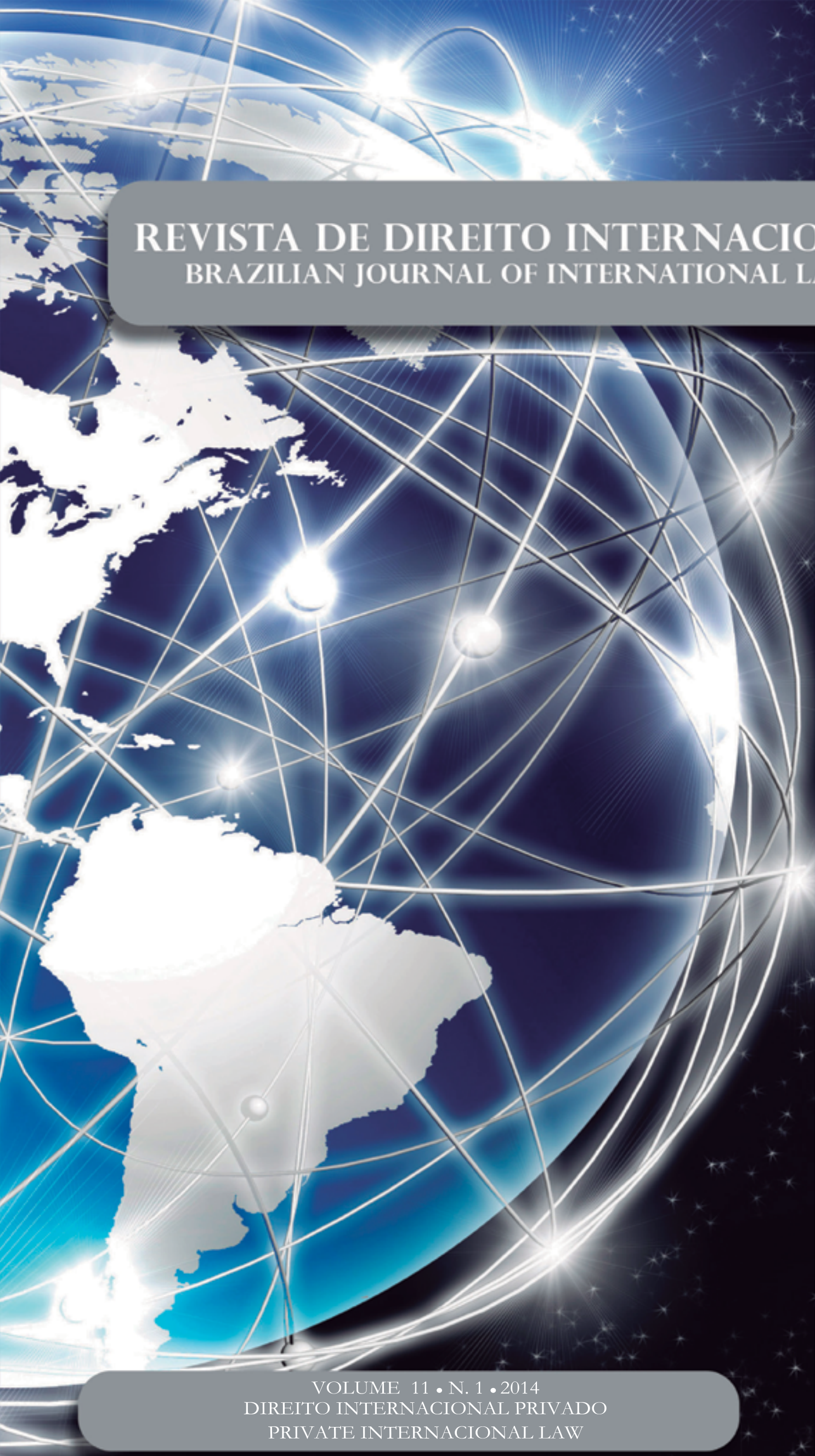

Direitos humanos: o paradoxo da condição humana e do mercado autorregulado

Human Rights: the paradox of the human condition and the selfregulatory market

Leilane Serratine Grubba 


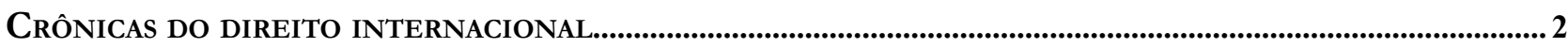

Nitish Monebhurrun

Alice Rocha da Silva

Julia Motte-Baumvol

Rafael Freitas de Oliveira

Roberta Greco

CRÔNICAS DO DIREITO INTERNACIONAL DOS INVESTIMENTOS .11

Nitish Monebhurrun

Reconhecimento E ExecuÇão de Sentenças Estrangeiras: anÁlise do projeto Em andamento na Conferência da Haia de Direito Internacional Privado

Nadia de Araujo

Fabrício Bertini Pasquot Polido

Os CASAMENTOS E AS PARCERIAS ENTRE PESSOAS DO MESMO SEXO NO DIREITO INTERNACIONAL PRIVAdO BRASILEIRO: ASPECTOS TRANSNACIONAIS DAS FAMÍLIAS CONTEMPORÂNEAS.

Bruno Rodrigues de Almeida

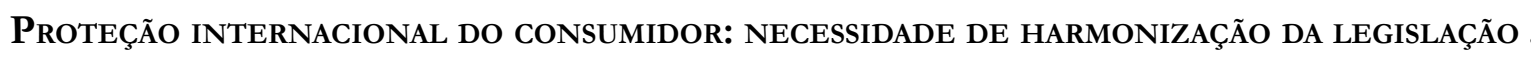
54

Héctor Valverde Santana

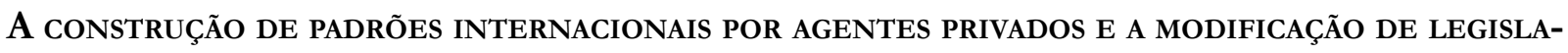
Ção NACIONAL: ALTERAÇÃo do PADRÃo DE CONTABILIDADE PARA EMPRESÁRIOS NO BRASIL.

Cleíse Nascimento Martins Costa

THE DEBATE ON COMPANIES' LIABILITY FOR INTERNATIONAL ENVIRONMENTAL DAMAGES: A COMPARISON BETWEEN THE JURISDiCTIONAL RULES OF THE EUROPEAN UNION AND THE UNITED STATES

Carina Costa de Oliveira

DesenVOlVIMENTO E APLICAÇÃo DA TEORIA dos VíNCUlOS MAIS ESTREITOS NO DIREITO INTERNACIONAL PRIVADO: POR UMA REDISCUSSÃO DO MÉTODO DE SOLUÇÃO DO CONFLITO DE LEIS 101

Jamile Bergamaschine Mata Diz

Rodrigo Vaslin Diniz

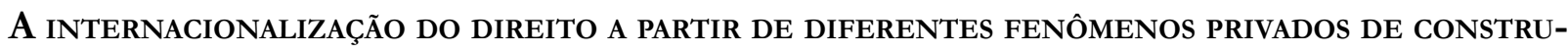
ÇÃO NORMATIVA 117

Fernando Lopes Ferraz Elias 
Leilane Serratine Grubba

Human TRAFFicking: IDENTIFYING FORCED LABOR IN MULTINATIONAL CORPORATIONS \& THE IMPLICATIONS OF LIABILITY

Tara M. Parente

Aplicação dos princípios UNIDROIT no Plano Brasil maior: o SUPRIMENTO de UMA lacuna NA POLÍTICA BRASILEIRA DE DESENVOLVIMENTO ECONÔMICO

Guilherme Freire de Melo Barros

Marcelle Franco Espíndola Barros

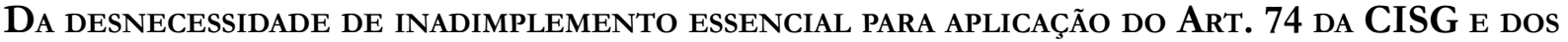
DANOS EFETIVAMENTE RECUPERÁVEIS

Renata Caroline Kroska

ESSAY ON UNEQUAL TREATIES AND MODERNITY THROUGH THE EXAMPLE OF BILATERAL INVESTMENT TREATIES

Nitish Monebhurrun

CONCEITOS DE RELAÇÕES INTERNACIONAIS E TEORIA DO DIREITO DIANTE DOS EFEITOS PLURALISTAS DA GLOBALIZAÇÃO: GOVERNANÇA GLOBAL, REGIMES JURÍDICOS, DIREITO REFLEXIVO, PLURALISMO JURÍDICO,

CORREGULAÇÃO E AUTORREGULAÇÃO . 216

Gabriela Garcia Batista Lima

\section{Outros Temas}

CONVENÇão SOBRE OS DIREITOS DAS PESSOAS COM DEFICIÊNCIA: COMO "INVISÍVEIS" CONQUISTARAM SEU ESPAÇO .230

Luana da Silva Vittorati

Matheus de Carvalho Hernandez 


\title{
Direitos humanos: o paradoxo da condição humana e do mercado autorregulado*
}

\section{Human Rights: the paradox of the human condition and the self-regulatory market}

\author{
Leilane Serratine Grubba**
}

\section{Resumo}

Este artigo busca compreender o discurso tradicional e ocidental dos direitos humanos, bem como a sua relação (ou não) com o paradoxo da condição humana e do mercado autorregulado. Nesse sentido, por meio do método dedutivo, o artigo analisará, em seu capítulo primeiro, o paradoxo da condição humana essencialista, pressuposto pelo discurso tradicional dos direitos humanos. Sequencialmente, o artigo analisará o paradoxo do mercado autorregulado. Este trabalho compreende que há relação indissociável entre o paradoxo do mercado autorregulado e a concepção de direitos humanos.

Palavras-chave: Direitos humanos. Paradoxo. Condição humana. Mercado. Dignidade.

\begin{abstract}
This article aims the human rights, and objectives to undertake a deconstruction the traditional and Western human rights discourse, and its relation with the paradox of the human condition and the regulated market. Accordingly, through the deductive method, this paper will analyze, in his first chapter, the paradox of essentialist human condition presupposed by traditional discourse of human rights. Sequentially, the article will examine the paradox of self-regulated market.
\end{abstract}

Key-words: Human rights. Paradox. Human condition. Market. Dignity.

\section{Introdução}

Os direitos humanos, como são entendidos tradicionalmente, referem-se aos textos jurídicos: são palavras (criações humanas). São o que o próprio verbo descreve: Convenções, Pactos, Declarações. Em suma, são o Direito Internacional

*Recebido em 03.02.2014

Aceito em 04.04.2014

${ }^{* *}$ Doutorado em direito em andamento (PPGD/UFSC). É mestre em direito (PPGD/UFSC), professora de direito (UFSC) e coautora dos livros Conhecer Direito I e Conhecer Direito II. E-mail:1sgrubba@hotmail.com dos Direitos Humanos e o Direito Nacional dos Direitos Humanos.

Para entendermos o que significa essa formulação dos direitos bumanos e as suas implicações sociais, culturais, econômicas e políticas, em primeiro lugar, também é necessário compreendermos, além dos processos de sua construção, que culminaram na universalização de uma única visão da natureza humana, dotada abstratamente de direitos, as fissuras desse discurso. Entender os direitos humanos também pressupõe entendermos os seus paradoxos mais latentes. 


\section{0 paradoxo da condição humana essencial}

Contemporaneamente, em pleno século XXI, ainda se utiliza de uma noção a-histórica dos direitos humanos que garante universalmente direitos a todos $\mathrm{e}$ todas, sendo o destinatário da norma uma espécie de ser humano essencialista e ideal (desvinculado do seu contexto geográfico, temporal, cultural, político, etc.), os direitos positivados em normativas nacionais e internacionais.

De fato, desde a Declaração Universal dos Direitos Humanos, ainda somos marcados pelo caráter individualista dos direitos - que envolve apenas os direitos à vida, à igualdade e à propriedade -, apesar da previsão de direitos sociais, assim como universalmente a-histórica e essencialista da natureza humana.

A Declaração, aprovada pela Assembleia Geral das Nações Unidas (1948), estabelece como seu fundamento a dignidade intrínseca e os direitos iguais e inalienáveis a todos os seres humanos. No mesmo sentido, Rodrigues $^{1}$ afirmou que, por meio "[...] desta ideia de direitos naturais da espécie humana, o discurso dos direitos humanos recorre a uma transcendentalização que os coloca fora da história e do contexto de seu surgimento e construção".

O discurso místico dos direitos humanos transforma os humanos em seres universais $\mathrm{e}$ essencialistas, ou seja, abstratos, deixando de lado os humanos concretos que vivem em sociedade. Esse ideal de humano, para usarmos a expressão de Bacon ${ }^{2}$, reside no seguinte fato "[...] a forma de uma natureza dada é tal que, uma vez estabelecida, infalivelmente se segue a natureza. Está presente sempre que essa natureza também o esteja, universalmente a afirma e é constantemente inerente a ela."

Nesse sentido, esbarramos num grande paradoxo do discurso dos direitos humanos, ou seja, o paradoxo da condição humana: é possível afirmar a existência de uma natureza humana eterna e imutável?

Em seu livro Teoria crítica dos direitos bumanos, Herrera Flores $^{3}$ relembra o livro intitulado El derecho de ser

1 RODRIGUES, Horácio Wanderlei. O discurso dos direitos humanos como veículo da dominação exercida pelos países centrais. In: CAUBET, Christian Guy. (Org.). O Brasil e a dependência externa. São Paulo: Acadêmica, 1989. p. 35-56.

2 BACON, Francis. Novum Organum ou verdadeiras indicações acerca da interpretação da natureza. Pará de Minas: M\&M, 2003. p. 67.

3 HERRERA FLORES, Joaquín. Teoria crítica dos direitos bumanos: os direitos humanos como produtos culturais. Rio de bombre, publicado pela Organização das Nações Unidas - UNESCO -, no qual o intento de rastrear, ao longo da história da humanidade, signos e vestígios que demonstrassem as raízes universais dos direitos humanos e não apenas enquanto conceitos ocidentais, ocultava a maneira pela qual se uniformizou e homogeneizou as distintas formas de vida e processos culturais. Em que pese o esforço intercultural, "[...] o que subjazia implicitamente era que os direitos humanos, tais como os entendemos no Ocidente, já estavam presentes nas manifestações mais primitivas da evolução humana".

Sob essa ótica ocidental, tanto a condição humana - fórmula de Hannah Arendt ${ }^{4}$ - quanto suas manifestações e, dentre elas, os direitos humanos, podem ser apresentados de maneira homogênea e naturalizados ao longo da história evolutiva.

A banalização do mal, noção extraída de Arendt ${ }^{5}$, pode ser entendida como uma detenção a essa contínua evolução do humano enquanto ser abstratamente detentor de direitos. $\mathrm{E}$ assim, principalmente depois do julgamento formal em Nuremberg dos genocídios nazistas, o conceito de condição humana foi utilizado como justificação ideológica do progresso dos direitos humanos.

As experiências nazistas foram consideradas exceções à condição humana. Contudo, adotar essa assertiva significa deixarmos de perceber as demais exceções, tão recorrentes que deveriam ser consideradas regras na história da humanidade. A título de exemplo, mencionaremos os genocídios franceses, portugueses, espanhóis.

Mencionamos como um exemplo atual o apoio militar, político e financeiro da França aos dirigentes Hutus, na Ruanda, em 1994, responsáveis pelo massacre de mais de 800 mil civis. Isso sem contar o genocídio francês durante a colonização da Argélia, em 1830, bem como durante o período da guerra de independência, intensificada a partir dos anos 50, do século XX.

Citamos também o tráfico negreiro de africanos em navios para serem vendidos como mercadorias nas colônias americanas. No Brasil, por exemplo, o projeto colonial de exploração das riquezas naturais resultou no tráfico de africanos para seres vendidos como escravos:

Janeiro: Lumen Juris, 2009. p. 49.

4 ARENDT, Hanna. A condição bumana. Rio de Janeiro: Forense Universitária, 2007.

5 ARENDT, Hanna. A condição bumana. Rio de Janeiro: Forense Universitária, 2007. 
foram cerca de 4 milhões de escravos negros vindos da África de maneira forçada ${ }^{6}$.

Aproximadamente 50,6\% da população brasileira, em 1817, era constituída de escravos, os quais morriam essencialmente de extenuação após 5 ou 7 anos de trabalho árduo e forçado ${ }^{7}$

Além de serem vendidos como mercadorias, os escravos pertenciam, tal como objetos, aos seus senhores, não gozando de nenhum direito. No Brasil, a escravidão somente foi abolida em 13 de maio de $1888^{8}$.

Em se tratando da América Latina, embora não seja possível afirmar uma unificação da configuração dos acontecimentos históricos, de maneira geral, a escassez de mão-de-obra, à época da colonização, motivou que trouxessem à força escravos africanos. Para tanto, a Coroa espanhola reservou para si o monopólio do comércio (des)bumano, que foi a mercadoria que mais gerou receitas para os cofres reais, tendo exercido por meio de concessões. Além disso:

\section{Essa exploração se tornou mais intensa e sistemática com a revolução industrial e tecnológica que chegou finalmente a nossas repúblicas... e continua chegando. Com ela é mantido um colonialismo econômico: os poderes do dinheiro continuação explorando o pobre, mas desta vez não em nome de uma distante metrópole, mas em nome dos princípios do capitalismo liberal $^{9}$}

Esse desenvolvimento da história da América Latina é criticado por Dussel ${ }^{10}$. A sua grande ressalva reside no fato de que, por mais que não possamos negar o núcleo libertário associado à Modernidade, tampouco podemos negar a face oposta desse processo de modernização, que se vincula ao exercício de violência nas colônias, física e cultural, bem como à postura assimilacionista ou à postura de eliminação, ambas voltadas à negação da diversidade.

6 ALDUNATE, José (Org.). Direitos humanos, direitos dos pobres: desafios da vida na sociedade. São Paulo: Vozes, 1991. (Série V). p. 36-44.

7 ALDUNATE, José (Org.). Direitos humanos, direitos dos pobres: desafios da vida na sociedade. São Paulo: Vozes, 1991. (Série V)

8 BEOZZO, José Oscar. História da Igreja no Brasil II. Petrópolis: Vozes, 1980. p. 259.

9 ALDUNATE, José (Org.). Direitos humanos, direitos dos pobres: desafios da vida na sociedade. São Paulo: Vozes, 1991. (Série V). p. 17-18.

10 DUSSEL, Enrique. 1492: o encobrimento do outro (a origem do mito da modernidade). Petrópolis: Vozes, 1993. p. 10-50.
Além disso, enquanto os nativos, os negros e os mestiços eram considerados inferiores e culpados por se negarem ao ajuste do modo civilizado de vida, os colonizadores eram percebidos como inocentes que buscavam ajudar os inferiores ${ }^{11}$.

No que toca à postura assimilacionista e eliminatória, a inversão da condição bumana reside no seguinte raciocínio: o povo nativo da América Latina - os indígenas - foi visto como igual no plano divino, o que gerou uma postura assimilacionista, a qual, por outro turno, não deixou de percebê-los como seres inferiores, visto que a vontade dos colonizadores foi imposta $^{12}$.

A recusa dos nativos em converterem-se à religião católica ou a negativa de entrega das riquezas, serviu como justificativa para o emprego de meios coercitivos, assim como a possibilidade da escravidão dos índios, raciocínio que desconhece a condição de sujeito dos povos nativos e a negação de sua bumanidade ${ }^{13}$.

Ora, se a população nativa da América Latina era tida como inferior, não deveriam ter agido civilizadamente os espanhóis, os quais, em nome dessa mesma noção de civilização, dizimaram populações inteiras? Sobre essa questão, dissertou Las Casas:

Faziam apostas sobre quem, de um só golpe de
espada, fenderia e abriria um homem pela metade,
ou que, mais habilmente e mais destramente, de
um só golpe lhe cortaria a cabeça, ou ainda sobre
quem abriria melhor as entranhas de um homem
de um só golpe. Arrancavam os filhos dos seios
da mãe e lhes esfregavam a cabeça contra os
rochedos enquanto que outros os lançavam à água
dos córregos rindo e caçoando, e quando estavam
na água gritavam: move-te, corpo de tal?! Outros, mais
furiosos, passavam mães e filhos a fio de espada ${ }^{14}$.

O que dizer da situação do México que, antes da conquista espanhola, era habitado por uma população aproximada de 25 milhões e após, em 1600, de apenas 1

11 DUSSEL, Enrique. 1492: o encobrimento do outro (a origem do mito da modernidade). Petrópolis: Vozes, 1993. p. 10-50.

12 TODOROV, Tzvetan. A conquista da América: a questão do outro. 3. ed. São Paulo: Martins Fontes, 1993. p. 11-15.

13 TODOROV, Tzvetan. A conquista da América: a questão do outro. 3. ed. São Paulo: Martins Fontes, 1993. p. 11-15.

14 LAS CASAS, Bartolomé de. Brevíssima relação da destruição das Índias: o paraíso destruído: a sangrenta história da conquista da América espanhola. Porto Alegre: L\&PM, 1991. p. 32. 
milhão? Para ilustrar, mencionamos a descrição de um massacre em uma aldeia asteca:

Um espanhol, subitamente, desembainha a espada (que parecia ter sido tomada pelo diabo), e imediatamente os outros cem fazem o mesmo, e começam a estripar, rasgar e massacrar aquelas ovelhas e aqueles cordeiros, homens e mulheres, crianças e velhos, que estavam sentados, tranquilamente, olhando espantados para os cavalos e para os espanhóis. Num segundo, não restam mais sobreviventes de todos os que ali se encontravam. Entrando então na casa grande, que ficava ao lado, pois isso acontecia diante da porta, os espanhóis começaram do mesmo jeito a matar a torto e a direito todos os que ali se encontravam, tanto que o sangue corria de toda parte, como se tivesse matado um rebado de vacas ${ }^{15}$.

Podemos falar que existe uma inversão discursiva que permitiu a justificação dessa (ir)racionalidade sob o manto da guerra justa? Ou seja, para alguns, a conquista e a destruição foram vistas como a possibilidade de fazer com que o bárbaro não-civilizado saísse dessa condição de barbárie.

Para outros, todavia, como o dominicano Bartolomé de Las Casas ${ }^{16}$, embora ainda possamos falar de uma postura assimilacionista, existiu o reconhecimento dos nativos na condição de sujeitos ao intentar a sua compreensão e não a sua submissão.

Houve, desde essa época, um pedido de tratamento mais humano aos nativos, mesmo que sob o manto assimilacionista. Por esse motivo é que Las Casas foi considerado o primeiro defensor dos direitos humanos na América Latina ${ }^{17}$.

E quanto ao Congresso de Berlim de 1885, que dividiu inteiramente a África entre as potências europeias e submeteu-a sob o império colonizador europeu? Mais recentemente, o que se afirmaria do neocolonialismo norte-americano e de alguns países europeus no território Afegão, após os ataques de 11 de setembro de 2001?

15 TODOROV, Tzvetan. A conquista da América: a questão do outro. 3. ed. São Paulo: Martins Fontes, 1993. p. 136-137.

16 LAS CASAS, Bartolomé de. Brevíssima relação da destruição das Índias: o paraíso destruído: a sangrenta história da conquista da América espanhola. Porto Alegre: L\&PM, 1991. p. 32.

17 DUSSEL, Enrique. 1492: o encobrimento do outro (a origem do mito da modernidade). Petrópolis: Vozes, 1993. p. 160-180.
E no que toca ao território Iraquiano, invadido sob a justificativa de livrar o país das garras do autoritarismo? Não foi esse território submetido perante outro autoritarismo, muito mais invasivo e mundial: o da própria concepção ocidental, principalmente NorteAmericana, de democracia, que findou na tentativa de submeter os iraquianos ao total do mercado e às concepções localistas ocidentais de como se impõe a organização de sua sociedade?

E a atual intervenção no território da Líbia, autorizada pela Organização das Nações Unidas em 2011, não somente em nome dos direitos humanos, mas principalmente em nome do princípio democrático? Não se referem esses exemplos, à banalização do mal?

Conforme afirmou Herrera Flores ${ }^{18}$, as exceções à condição humana estão presentes de modo tão reiterado na história que se deve suspeitar se a maior banalização do mal não seria deixar de considerar que a verdadeira desumanização são os atos que impedem o ser humano de assumir-se enquanto ser humano, dotado de potencialidade de lutar por sua igualdade e liberdade, bem como de fazer valer sua concepção de sociedade e seu modelo de organização sociocultural e política.

Prosseguiremos, então. Hugo Grotius (Grócio), considerado frequentemente o fundador do direito internacional público, foi um dos maiores expoentes do jusnaturalismo. Sua obra se caracterizou pela tentativa de conduzir o contexto internacional do século XVII, marcado por um longo período de guerras, a um equilíbrio e ao resgate da paz para a manutenção das relações entre os Estados ${ }^{19}$.

Seu texto, on the law of war and peace - De jure belli ac pacis - tentou fornecer um sistema metódico de jurisprudência natural - jus gentium - para o elogio à paz como bem fundamental da sociedade internacional ${ }^{20}$.

Contratado pela Companhia Holandesa das Índias Orientais, Grócio publicou Mare Liberum, no qual, ao tratar do problema da jurisdição dos oceanos, das rotas marítimas e das novas terras descobertas, aventou princípios legitimadores da expansão marítima holandesa, assim como um questionamento a respeito da extensão da soberania dos Estados, visando à

18 HERRERA FLORES, Joaquín. Teoria critica dos direitos humanos: os direitos humanos como produtos culturais. Rio de Janeiro: Lumen Juris, 2009. p. 52.

19 GROTIUS, Hugo. On the law of war and peace. Londres. 1814.

20 GROTIUS, Hugo. On the law of war and peace. Londres. 1814. 
incorporação de novas regiões - legitimação do colonialismo $^{21}$.

Como considerar esse autor, então, um dos pais do direito das gentes e defensor da paz, quando, por outro lado, sob ordens da Companhia Holandesa das Índias, defendeu o colonialismo e a rapina dos territórios sob a soberania dos Estados europeus?

Mais do que isso, o que falar da atitude ambivalente dos Estados Unidos da América que, ao mesmo tempo em que reclama o respeito e o cumprimento dos direitos humanos por parte de todos os demais países, mantém centenas de pessoas condenadas à pena capital, na angústia de esperar a morte, que pode ocorrer imediatamente ou em um futuro incerto.

Ou então, o que falar daqueles que, em nome do direito à vida, lutam pela vedação dos meios de interrupção da gravidez, normalmente em razão de fins religiosos, ou daqueles que, por detrás da defesa de uma política de paz, apoiam a liberalização do aborto? ${ }^{22}$. Nesse sentido, parece que os direitos humanos se encontram no interstício, ora se configurando como produtos culturais, ora aos reclamos ideológicos.

A Turquia, por exemplo:

[...] censura o ocidente de utilizar a questão dos direitos humanos para desacreditar os Estados não-ocidentais, considerando-a um instrumento do neocolonialismo. Mas também a universalidade dos direitos humanos em si mesma é questionada. A Turquia invoca sua tradição cultural específica que a autorizaria a defender sua própria concepção de direitos humanos e a adotar uma atitude também específica a este respeito ${ }^{23}$.

Seguindo o caminho traçado, ocidentalmente, preceituam-se os direitos humanos sob a noção de geração de direitos, por meio de uma linha temporalevolutiva unilateral, segundo a qual os direitos vão se sucedendo uns aos outros a partir da própria evolução da condição humana.

Segundo Herrera Flores ${ }^{24}$, a construção da ideia de geração de direitos não é neutra, tampouco possui efeitos

21 GROTIUS, Hugo. The freedom of the seas. New York: Oxford University Press, 1916.

22 FLEINER, Thomas. O que são direitos humanos? São Paulo: Mas Limonad, 2003. p. 16.

23 FLEINER, Thomas. O que são direitos humanos? São Paulo: Mas Limonad, 2003. p. 44.

24 HERRERA FLORES, Joaquín. Teoria crítica dos direitos bumanos: os direitos humanos como produtos culturais. Rio de meramente retóricos ou pedagógicos. Constituindose a partir de um rol ontológico de direitos universais, pressupõe sempre uma superação dos direitos já conquistados em determinado momento histórico.

Para bem ilustrar a confusão a que remete o termo gerações, Arruda Júnior e Gonçalves ${ }^{25}$ podem expor os seguintes questionamentos:

a) quem se diz livre (primeira geração), quando não tem acesso a um emprego (segunda geraşão)?

b) é possível afirmar a igualdade (primeira geração) de quem não possui educação (segunda geração)?

c) exerce seu direito ao sufrágio universal (primeira geração), quem trocou seu voto por alimento ou quem não possui conhecimentos suficientes para deliberar sobre a escolha do candidato (segunda geração)?

d) como compreender o direito à vida (primeira geração) de alguém que não tem acesso à saúde (segunda geração)?

Nesse mesmo sentido, quando se referem aos direitos fundamentais, Lamy e Rodrigues ${ }^{26}$ se preocupam em utilizar o termo dimensões dos direitos em detrimento ao termo gerações. Primeiramente, em razão de que o termo substitutivo melhor se refere ao desenvolvimento histórico dos direitos. Em segundo lugar, buscam evitar a falsa noção de sucessão dos direitos no tempo, ao invés da necessidade da garantia de todas as dimensões conjuntamente.

Conforme Sarlet ${ }^{27}$, a discordância reside essencialmente na esfera terminológica: o termo geração de direitos. Existe um consenso no que tange ao conteúdo das ditas gerações de direitos, visto que se refere aos direitos que foram sendo positivados, tanto em âmbito nacional quanto internacionalmente, em determinadas épocas históricas.

Se por um lado, não podemos negar o reconhecimento progressivo de novos direitos, por outro lado, ao utilizarmos a expressão geração de direitos podemos ensejar a imagem de uma falsa substituição

Janeiro: Lumen Juris, 2009. p. 52-53.

25 ARRUDA JÚNIOR, Edmundo Lima de; GONÇALVES, Marcus Fabiano. Direito: ordem e desordem, eficácia dos direitos humanos e globalização. Florianópolis: IDA, 2004. p. 29.

26 LAMY, Eduardo de Avelar; RODRIGUES, Horácio Wanderlei. Curso de processo civil: teoria geral do processo. Florianópolis: Conceito, 2010. v. 1. p. 161-162.

27 SARLET, Ingo Wolfgang. A eficácia dos direitos fundamentais: uma teoria geral dos direitos fundamentais na perspectiva constitucional. 10. ed. Porto Alegre: Livraria do Advogado, 2010. p. 45. 
gradativa desses direitos, como se a positivação de novos direitos tivesse o condão de sobrepô-los aos anteriormente positivados, bem como a falsa impressão de que não existe mais necessidade de garantia dos anteriores ${ }^{28}$.

Todavia, os direitos positivados não se substituem ao longo do tempo, mas se encontram em processo contínuo de expansão, cumulação e de garantia ${ }^{29}$.

Decorre desse problema a noção da indivisibilidade dos direitos, o que significa serem eles não-bierarquizáveis, ou seja, é vedada a justificação da efetivação de alguns direitos (principalmente os direitos individuais), em detrimento dos demais ${ }^{30}$.

Romper com a noção de geração de direitos e sua consequência mais óbvia, a passividade e inação a que leva aos humanos à luta pela dignidade humana, ante a aparência de conquista evolutiva dos direitos, pressupõe a decisão de, em todas as análises, partirmos dos contextos reais.

A condição humana é condicionada aos contextos reais nos quais o humano vive e, por consequência, varia geográfica, espacial e temporalmente. Não é, nem pode ser, linear ou evolutiva. Pressupõe quebras, rupturas, prosseguimentos e retrocessos.

Os direitos humanos, enquanto reação aos contextos - social, político, econômico, etc. - nos quais os humanos habitam, não depositam sua validade ou justiça em critérios geracionais, pois toda a forma de luta pela dignidade tem igual importância. Sua validade reside na aptidão que estas manifestações e lutas adquirem à hora de ascender aos bens materiais $\mathrm{e}$ imateriais necessários a uma vida digna.

Nesse sentido, a condição humana, para além de ser condicionada, também é condicionante, visto que por meio das atuações contrárias aos processos injustos de divisão do fazer humano, também podemos construir positivamente as condições concretas aptas a garantir a dignidade e a vida em igualdade substancial.

\section{O paradoxo do mercado global autorregulado}

28 SARLET, Ingo Wolfgang. A eficácia dos direitos fundamentais: uma teoria geral dos direitos fundamentais na perspectiva constitucional. 10. ed. Porto Alegre: Livraria do Advogado, 2010. p. 45.

29 TRINDADE, Antonio Augusto Cançado. Tratado de direito internacional dos direitos bumanos. Porto Alegre: Fabris, 1997. v. 1. p. 24-25.

30 TRINDADE, Antonio Augusto Cançado. Tratado de direito internacional dos direitos humanos. Porto Alegre: Fabris, 1997. v. 1. p. 25.
O próximo paradoxo é a questão do mercado. $\mathrm{O}$ mercado não só é o grande paradoxo, como também foi e continua sendo a grande aposta. Historicamente, o mercado pode ser definido como um conjunto de normas, procedimento e regras que foram regulando a produção e o intercâmbio de bens.

Contudo, conforme Williams ${ }^{31}$, esse conceito (descrição) difere em muito da concepção de mercado que se iniciou com a modernidade ocidental e o novo modo de produção (mercado autorregulado), que renega quaisquer conjuntos de normas ou procedimentos que obstaculizem, mesmo que minimamente, a premissa básica de acumulação desenfreada do capital.

No sentido acima delineado por Williams ${ }^{32}$, mencionamos o expoente da ciência econômica clássica, Adam Smith $^{33}$. Em seu livro $A$ riqueza das nações, considerou que a riqueza das nações deriva da liberdade de mercado, instituição esta que modernamente foi apropriada em sua integridade pelo capital.

Ou seja, existe um gradativo desaparecimento das regulações de intercâmbios de bens, do ponto de vista do valor do uso, para o aparecimento e desenvolvimento do intercambio pautado pelo valor da troca (processo de acumulação) $)^{34}$.

A substituição do valor de uso das mercadorias pelo valor de troca gera um processo contínuo e irrestrito de acumulação do capital, produtor de aparente escassez que só faze aumentar o valor da acumulação, sempre oposta a qualquer tipo de regra possa diminuir ou obstaculizar seu crescente avanço.

O mercado converte-se em uma entidade que admite somente suas próprias regras e procedimentos: torna-se autorregulado. Podemos falar, nesses termos, da mão invisível do mercado ${ }^{35}$.

Ante o convívio, por mais de sessenta anos, da instituição do mercado juntamente com os direitos humanos, não seria possível considerarmos que a mão

31 WILliAMS, Raymond. El campo y la ciudad. Buenos Aires, Barcelona, México: Paidós, 2001.

32 WILliAMS, Raymond. El campo y la ciudad. Buenos Aires, Barcelona, México: Paidós, 2001.

33 SMITH, Adam. A riqueza das nações: investigação sobre sua natureza e suas causas. São Paulo: Nova Cultura, 1996.

34 SMITH, Adam. A riqueza das nações: investigação sobre sua natureza e suas causas. São Paulo: Nova Cultura, 1996.

35 SMITH, Adam. A riqueza das nações: investigação sobre sua natureza e suas causas. São Paulo: Nova Cultura, 1996. p. 438. 
invisível do mercado é, de tal forma, tão invisível, que penetra no próprio conceito dos direitos humanos?

Conforme afirmou Herrera Flores ${ }^{36}$, no que toca aos direitos humanos, os direitos individuais se sobressaem, uma vez que não necessitam de intervenção alheia. Já os direitos sociais, econômicos e culturais sofrem um processo de degradação, visto que necessitam de intervenções ${ }^{37}$.

Por esse motivo, Rodrigues ${ }^{38}$ afirma que o discurso dos direitos humanos serve "[...] como instrumento ideológico de legitimação da dominação capitalista sobre o terceiro mundo." Isso explica o fato de os direitos individuais e políticos, de origem burguesa e caráter liberal, se sobreponham aos demais direitos, que demandam uma modificação estrutural na sociedade de cunho econômico.

Assim, quando falamos em direitos humanos, os direitos individuais, civis e políticos são plenamente exigíveis e são acompanhados de mecanismos jurídicos à sua satisfação.

Todavia, no âmbito do Estado Democrático liberal, os direitos sociais, econômicos e culturais formalizaram-se enquanto normas programáticas, pois que não possuem normas jurídicas que as garantam, nem tampouco possibilidade de concreta cobrança jurídica para a sua efetivação.

E assim, resulta que o mercado e seu conjunto de regras e procedimentos que legitimam a ordem capitalista, em ultima instância, vai selecionar quais os direitos a serem implementados em detrimentos dos demais.

Por isso, devemos compreender que os seres humanos estão imersos em variadas relações, que podem ser necessárias e independentes da sua vontade e que, essencialmente, se configuram como relações de produção, as quais correspondem diretamente ao grau de desenvolvimento das suas formas produtivas materiais.

Ora, o conjunto dessas relações de produção constitui a estrutura (base) econômica da sua sociedade, que por

36 HERRERA FLORES, Joaquín. Teoria crítica dos direitos humanos: os direitos humanos como produtos culturais. Rio de Janeiro: Lumen Juris, 2009. p. 61.

37 LAMY; RODRIGUES, 2010, p. 170; SARLET, 2010, p. 248.

38 RODRIGUES, Horácio Wanderlei. O discurso dos direitos humanos como veículo da dominação exercida pelos países centrais. In: CAUBET, Christian Guy. (Org.). O Brasil e a dependência externa. São Paulo: Acadêmica, 1989. sua vez não deixa de se estabelecer como a base concreta sobre a qual se ergue uma superestrutura jurídica e política e às quais correspondem determinadas formas de consciência social.

Nesse sentido, tanto a vida social, política, intelectual, etc., condicionam o modo de produção da vida material, quanto o próprio modo de produção da vida material condiciona o processo da vida, podendo incluir os humanos como sujeitos do suposto pacto social, mas também alijá-los ${ }^{39}$.

Já no ano de 1990, o primeiro Relatório de Desenvolvimento Humano - PNDU, das Nações Unidas (1990), apresentou o recém-criado Índice de Desenvolvimento Humano - IDH, cuja premissa maior residia na consideração de que a questão econômica de uma determinada região (rendimento nacional) deveria ser necessariamente vinculada a outras questões, de cunho econômico, mas essencialmente social, como a esperança de vida e a alfabetização.

Salientamos que o desenvolvimento humano, além de estar relacionado com a saúde, a educação e ao rendimento (parâmetros utilizados pelo índice), também se vincula à equidade, à sustentabilidade e à liberdade. Assim, por mais que o IDH indique uma progressão no desenvolvimento, esse fato não implica, necessariamente, a exclusão das dimensões mais amplas não abrangidas.

Por isso, é possível que um país apresente um IDH elevado e, ao mesmo tempo, ser insustentável, não democrático e não equitativo, da mesma forma em que é possível que um país detenha um IDH baixo, mas que seja relativamente sustentável, democrático e equitativo. Esse fato em razão de que não existe um padrão direto que relacione o IDH às demais dimensões do desenvolvimento, excetuada a desigualdade, que se relaciona negativamente com o IDH.

Devemos mencionar que o IDH não objetiva se constituir em um indicador inatacável do bem-estar, mas em redirecionar as atenções de todos e todas no sentido do desenvolvimento humano, visando promover o debate para fazer progredir as sociedades contemporâneas.

Para tanto, o IDH reflete o resultado da conexão de quatro indicadores, os quais se refletem em três dimensões, ou seja: o indicador da esperança de vida à

39 MIAILLE, Michel. Uma introdução crítica ao direito. Lisboa: Moraes, 1979. p. 64. 
nascença (dimensão da saúde), os indicadores de média de anos de escolaridade e de anos de escolaridades esperados (dimensão da educação) e indicador do rendimento nacional bruto per capita (dimensão de padrões de vida). Assim, o IDH é a média geométrica dos três índices de dimensão. Trata-se de um método que captura o nível de desempenho de um país em todas as três dimensões ${ }^{40}$.

Não obstante esse primeiro índice ter considerado apenas as médias nacionais, as quais desconsideravam as assimetrias de distribuição, expressou a medida a ser perseguida futuramente: as pessoas são a verdadeira riqueza de uma nação. Essa foi a grande visão do economista indiano Amartya $\operatorname{Sen}^{41}$ e do criador do Relatório, o paquistanês Mahbub ul-Haq.

Vinte anos depois, no Relatório de 2010, tornou-se muito mais concreta a visão de que o sucesso de um país ou mesmo o bem-estar de um indivíduo não podem ser considerados apenas pela questão monetária. Embora importante, visto que sem recursos, o desenvolvimento se torna quase impossível dentro da lógica capitalista, é necessária a avaliação da qualidade e quantidade da vida (longevidade), da educação, quantitativa e qualitativamente, a capacidade de utilização crítica do conhecimento e a escolha do próprio destino ${ }^{42}$.

Em última instância, o bem-estar pouco tem a ver com o dinheiro e muito mais com o desenvolvimento, com as possibilidades que cada um e cada uma tem de optar por planos de vida e caminhar ao encontro deles. Diante disso, a Organização das Nações Unidas, por meio do Relatório de Desenvolvimento Humano, apelou para uma economia renovada, isto é, uma economia de desenvolvimento humano, na qual o principal objetivo é aumentar o bem-estar humano e o seu crescimento, a curto e longo prazo ${ }^{43}$.

40 ORGANIZAÇÕES DAS NAÇÕES UNIDAS. Relatório de desenvolvimento bumano 2010: a verdadeira riqueza das nações: vias para o desenvolvimento humano. Disponível em: <http://hdr.undp.org/ en/media/HDR_2010_PT_Complete_reprint.pdf > . Acesso em: 30 mar. 2011.

41 SEN, Amartya. Poverty and Famines: an essay on Entitlement and Deprivation. Nova Iorque: Oxford University Press, 1983.

42 ORGANIZAÇÕES DAS NAÇÕES UNIDAS. Relatório de desenvolvimento bumano 2010: a verdadeira riqueza das nações: vias para o desenvolvimento humano. Disponível em: <http://hdr.undp.org/ en/media/HDR_2010_PT_Complete_reprint.pdf > . Acesso em: 30 mar. 2011.

43 ORGANIZAÇÕES DAS NAÇÕES UNIDAS. Relatório de desenvolvimento humano 2010: a verdadeira riqueza das nações: vias para o desenvolvimento humano. Disponível em: <http://hdr. undp.org/en/media/HDR_2010_PT_Complete_reprint.pdf $>$.
Daí porque, consoante o Relatório, as políticas derivadas do Consenso de Washington se tornaram prescrições universalizadas indefensáveis, embora ainda praticadas. A importância reside nas teorias sobre o desenvolvimento que lhe são antagonicamente concorrentes, as quais compartilham do reconhecimento da necessidade de uma ação pública de regulação da economia para a proteção do ser humano, notadamente os que se encontram em situação vulnerável (saúde, educação, ameaças climáticas, etc.), bem como percebem que a luta pela redução da pobreza implica na alteração dos níveis de distribuição dos rendimentos ${ }^{44}$.

O progresso do IDH é patente. Todavia, ao longo de 40 anos (1970-2010), os melhoramentos no campo da saúde e da educação não foram acompanhados de um real melhoramento no quesito rendimento. Esse fato nos leva a considerar a importância da análise da complexidade econômica.

Até porque, conforme Charles Kenny ${ }^{45}$, inexiste uma correlação absoluta entre as três esferas acima mencionadas: o crescimento econômico não é indispensável ao progresso na saúde e na educação.

Podermos extrair desse discurso a desnecessidade de uma distribuição equitativa de rendimentos para angariar o progresso humano, legitimadora do capitalismo moderno. Ainda assim, parece imprescindível entender a real importância da consideração da análise econômica, esfera que influi, em que pese não absolutamente, em todas as demais facetas da vida humana.

Portanto, existe uma relação causal, visto que rendimentos mais elevados determinam uma melhor qualidade de vida, de saúde e de educação, ao passo que a maior qualidade dessas três instâncias podem tornar as sociedades mais produtivas. Nesse sentido, segundo as Nações Unidas:

[...] rendimento aumenta o domínio das pessoas
sobre os recursos necessários para a obtenção de
acesso a comida, abrigo, vestiário e opções de vida
mais amplas. Esses recursos também possibilitam

Acesso em: 30 mar. 2011.

44 ORGANIZAÇÕES DAS NAÇÕES UNIDAS. Relatório de desenvolvimento humano 2010: a verdadeira riqueza das nações: vias para o desenvolvimento humano. Disponível em: <http://hdr.undp.org/ en/media/HDR_2010_PT_Complete_reprint.pdf >. Acesso em: 30 mar. 2011. p. 21.

45 KENNY, Charles. There's more to life than money: exploring the levels/growth paradox in health and education. Journal of international development, v. 21, n. 1, p. 24-41, 2009. 
que as pessoas avancem com os seus planos de vida sem estarem excessivamente limitadas pelas necessidades materiais - como o trabalho em atividades significativas e intrinsecamente compensadoras ou a passagem de mais tempo com os entes queridos. [...] Os nossos resultados não negam a importância do rendimento mais elevado para o aumento do acesso das pessoas pobres a serviços de saúde e educação, um resultado extensivamente documentado na literatura microeconómica. A forte correlação entre a situação sócio-económica e a saúde numa sociedade reflecte, com frequência, a vantagem relativa das pessoas mais ricas na obtenção de acesso a serviços de saúde ${ }^{46}$.

A ausência de determinação absoluta significa que estamos tratando de um índice global (médio) de rendimento das diversas localidades, o que não leva a uma análise pormenorizada das disparidades de rendimento real entre as pessoas de uma região.

O que não podemos deixar de verificar, em absoluto, é que a complexidade econômica (e financeira do capital globalizada) influi na possibilidade de se alcançar e manter uma vida digna de ser vivida.

Para exemplificar esse fato, salientamos que, com a crise financeira global ocasionada pelo rebentar da bolha imobiliária e pelos colapsos dos bancos estadunidenses, que se estenderam rapidamente à maior parte do mundo, 34 milhões de pessoas perderam o emprego e 64 milhões de pessoas se situaram em padrão abaixo do nível da pobreza (menos de 1,25 dólares por dia). Além disso, outras aproximadas 160-200 milhões de pessoas ficaram em situação de pobreza em razão dos aumentos dos preços das mercadorias nos anos seguintes.

Mais do que isso, segundo o RDH 2010, das Nações Unidas:

[se] os países desenvolvidos foram os mais duramente atingidos pela crise, a capacidade de alguns países em desenvolvimento lidarem com os seus efeitos é mais limitada. Cerca de $40 \%$ dos países que enfrentam um abrandamento do crescimento já tinham uma alta taxa de pobreza em 2009 e reduzidas capacidades fiscais

46 ORGANIZAÇÕES DAS NAÇÕES UNIDAS. Relatório de desenvolvimento bumano 2010: a verdadeira riqueza das nações: vias para o desenvolvimento humano. Disponível em: <http://hdr.undp.org/ en/media/HDR_2010_PT_Complete_reprint.pdf $>$. Acesso em: 30 mar. 2011. p. 50-51. e institucionais para lidar com a volatilidade econômica. [...] Os impactos sobre os rendimentos dependem da existência ou não de sistemas adequados de apoio ao desemprego. [...] Quando não existe proteção social, as pessoas que perdem o emprego são obrigadas a fazer a transição para a economia informal, onde os salários são mais baixos e a vulnerabilidade é superior ${ }^{47}$.

Que podemos falar dessas novas milhões que pessoas que se juntaram aos milhões que já sofriam de ausência da possibilidade de um mínimo de dignidade e vida digna? É necessário que as sociedades definam a melhor opção se regras básicas para as relações entre o Estado, a sociedade, as empresas e os trabalhadores, visando assegurar direitos básicos.

Ao invés de crermos na universalidade de receitas político-econômicas, devemos incentivar as estratégias de desenvolvimento contextuais, visando a melhor opção possível para políticas redistributivas e para a promoção da igualdade/equidade.

O bem-estar e a vida digna envolvem muito mais do que o dinheiro, do que o capital. Falamos de acesso a bens materiais e imateriais, de uma vida a valorizar, com saúde, educação, identidade cultural, etc.

As políticas do desenvolvimento humano, nesse sentido, devem estar integradas a uma estrutura que apoie um crescimento com equidade e a sustentabilidade.

Nesse sentido, segundo o RDH 2010, das Nações Unidas, no que toca à sustentabilidade, já desde a primeira Cimeira da Terra no Rio de Janeiro, ou seja, ao longo de vinte anos, se demonstrou a importância do ambiente e da preservação dos recursos naturais para o desenvolvimento. Diante disso:

\footnotetext{
Enfrentamos enormes desafios em questões como as reservas de água, a degradação do solo, as alterações climáticas e uma perda generalizada de diversidade biológica e de serviços ecológicos, desafios esses que levantam novas dificuldades para a promoção do crescimento e do progresso mais vasto no desenvolvimento humano. Uma fraca gestão dos recursos naturais e do ambiente cria uma carga mais pesada para os pobres, que geralmente dependem mais destes recursos para a
}

47 ORGANIZAÇÕES DAS NAÇÕES UNIDAS. Relatório de desenvolvimento bumano 2010: a verdadeira riqueza das nações: vias para o desenvolvimento humano. Disponível em: <http://hdr.undp.org/ en/media/HDR_2010_PT_Complete_reprint.pdf $>$. Acesso em: 30 mar. 2011. p. 84-86. 
sua subsistência e não dispõe de activos para se adaptarem a estas alterações ou absorverem este custo adicional. [...] Os danos ambientais não são um exemplo isolado. [...] não é que o crescimento e o desenvolvimento humano não possam avançar em conjunto, mas sim que é um erro grave considerar as reformas políticas e institucionais apenas quanto aos seus efeitos no rendimento, como faz uma grande parte da literatura dedicada ao crescimento. Daí o nosso apelo para uma economia de desenvolvimento humano ${ }^{48}$.

Justamente nesse sentido, podemos situar a importância da teologia da libertação para a defesa dos direitos dos pobres, principalmente no âmbito da América Latina. Com raízes na Escritura cristã, tomou a forma, nas obras de teólogos latino-americanos, de uma teoria dos direitos dos pobres, comprometida com a práxis e a libertação ${ }^{49}$.

Existe uma releitura da palavra de Deus e da Igreja, para se construir uma teoria que corresponda à prática social de emancipação e libertação dos pobres, a partir da conscientização dos direitos e de sua condição de desigualdade. Para a teoria (ou teologia) da libertação, os direitos humanos devem ser entendidos também como direitos dos pobres ${ }^{50}$.

Devemos ter em mente que, ao deixar de lutar pelos direitos humanos, porque os consideramos, tal como são concebidos, funcionais ao capital, também deixamos cada vez mais fissuras para que o capital continue a penetrar.

Por mais que os direitos humanos tenham surgido como reações da burguesia, ao lado e, conjuntamente, ao aparecimento das relações sociais baseadas no capital e sejam a elas funcionais, ainda hoje em dia, ao invés de abandonarmos a luta pela dignidade humana, devemos nos posicionar criticamente, reconhecendo a realidade das manifestações de ditas relações e o papel que cumprem simbolicamente os instrumentos de

48 ORGANIZAÇÕES DAS NAÇÕES UNIDAS. Relatório de desenvolvimento bumano 2010: a verdadeira riqueza das nações: vias para o desenvolvimento humano. Disponível em: <http://hdr.undp.org/ en/media/HDR_2010_PT_Complete_reprint.pdf > . Acesso em: 30 mar. 2011. p. 110-120.

49 ALDUNATE, José (Org.). Direitos humanos, direitos dos pobres. desafios da vida na sociedade. São Paulo: Vozes, 1991. (Série V). p. 178-200.

50 ALDUNATE, José (Org.). Direitos humanos, direitos dos pobres. desafios da vida na sociedade. São Paulo: Vozes, 1991. (Série V). p. 178-200. direitos humanos para que possamos reinventar novos modos alternativos de luta pela vida digna.

Nesse sentido, Herrera Flores $^{51}$ nos propõe pensarmos renovadas epistemologias e vias jurídicas, adequadas ao presente contexto mundial, ao invés de tornarmo-nos meros céticos impotentes ante os meios políticos, econômicos e jurídicos do liberalismo progressista keynesiano.

Dentre os dogmas do liberalismo, prevalece à prioridade do direito sobre o bem: necessita-se e lutase por direitos, não por bens aptos a garantir uma vida digna. E assim, todos os humanos têm direito à vida, porém milhões morrem diariamente por não ter o que comer.

Todos os humanos têm direito à saúde, mas milhares morrem de doenças evitáveis, de doenças já extintas, ou em virtude dos genocídios ocasionados por testes farmacológicos em regiões da África subsaariana ${ }^{52}$.

Garante-se a partir dos direitos, como passo necessário e anterior à dignidade, somente os valores hegemônicos, em razão dos processos de divisão do fazer humano, que faz com que uns possam ascender aos bens por meio dos direitos e que, para outros, seja difícil ou impossível.

O liberalismo constrói a noção de uma liberdade baseada no seguinte postulado: minha liberdade termina quando e onde comesa a do outro.

Isso significa que a liberdade do indivíduo enquanto auto-realização em condições de igualdade e justiça social, não como autonomia individual, devem ser protegidas do próprio liberalismo que, na sociedade capitalista contemporânea, transformou a liberdade em retórica, a exemplo da liberdade individual de expressão, e concentrou, cada vez mais, o poder político e poder econômico ${ }^{53}$.

Portanto, não há sequer uma obrigação que tenha o condão de me fazer ajudar o outro, pois a liberdade dele também somente se inicia de modo alheio e

51 HERRERA FLORES, Joaquín. Teoria crítica dos direitos bumanos: os direitos humanos como produtos culturais. Rio de Janeiro: Lumen Juris, 2009. p. 65.

52 ORGANIZAÇÕES DAS NAÇÕES UNIDAS. Relatório de desenvolvimento bumano 2010: a verdadeira riqueza das nações: vias para o desenvolvimento humano. Disponível em: <http://hdr.undp.org/ en/media/HDR_2010_PT_Complete_reprint.pdf > . Acesso em: 30 mar. 2011.

53 SÁNCHEZ VÁZQUEZ, Adolfo. Entre a realidade e a utopia: ensaios sobre política, moral e socialismo. Rio de Janeiro: Civilização Brasileira, 2001. p. 259. 
desvinculado da minha. Esse postulado tem forte influência ideológica para a legitimação da noção de propriedade privada.

Por mais que um discurso não se baseie em fatos da realidade, tende, além de justificar uma determinada concepção, criar realidade. Modernamente, assistimos a tentativa de justificação e legitimação de uma hegemonia global baseada em somente um sistema de valores, o do mercado autorregulado e da democracia reduzida aos seus aspectos puramente formais e eleitorais.

Sob essa ótica, os direitos humanos não escaparam dos enfoques dominantes e são utilizados, discursivamente, tanto para criar quanto para legitimar essa mesma realidade criada pela ideologia do capital globalizado.

\section{Conclusão}

$\mathrm{O}$ artigo teve por objeto os direitos humanos e objetivou proceder a uma desconstrução do discurso tradicional e ocidental dos direitos humanos, em razão da análise de dois seus paradoxos mais manifestos.

Nesse sentido, o artigo analisou, em seu capítulo primeiro, o paradoxo da condição humana essencial, pressuposto pelo discurso tradicional dos direitos humanos. Conforme vimos, atualmente ainda existe uma noção dos direitos humanos que garante universalmente a todas as pessoas, direitos. Com isso, temos a ideia de um ser humano essencialista e idealista, completamente desvinculado do seu contexto geográfico, temporal, cultural, político, etc.

O paradoxo da condição humana nos questiona se é possível afirmar a existência de uma natureza humana eterna e imutável. Parece que as atrocidades não foram exceções na história da humanidade, mas foram tão recorrentes que deveriam ser consideradas a regra geral.

Nesse sentido, as exceções à condição humana estão presentes de modo tão reiterado na história que se deve suspeitar se a maior banalização do mal não seria deixar de considerar que a verdadeira desumanização são os atos que impedem o ser humano de assumirse enquanto ser humano, dotado de potencialidade de lutar por sua igualdade e liberdade, bem como de fazer valer sua concepção de sociedade e seu modelo de organização sociocultural e política.

Entendemos que não existe uma condição humana essencialista e eterna, mas que ela é condicionada pelos contextos reais nos quais o ser humana vive. Justamente por isso, ela varia espacial, geográfica e temporalmente.

Sequencialmente, o artigo analisou o paradoxo do mercado autorregulado. O mercado moderno se converteu numa entidade que admite somente suas próprias regras e procedimentos, isto é, ele se tornou autorregulado. Mais do que isso, após o convívio de mais de sessenta anos da instituição do mercado com os direitos humanos, parece que a mão invisível do mercado penetrou no próprio conceito dos direitos humanos.

Diante disso, os direitos individuais não necessitam da intervenção do estado, visto serem direitos de liberdade. Já os direitos sociais, econômicos e culturais sofrem um processo de degradação, visto que necessitam de intervenções.

Quando falamos em direitos humanos, os direitos individuais, civis e políticos são plenamente exigíveis e são acompanhados de mecanismos jurídicos à sua satisfação. Todavia, os direitos sociais, econômicos e culturais formalizaram-se enquanto normas programáticas, pois que não possuem normas jurídicas que as garantam, nem tampouco possibilidade de concreta cobrança jurídica para a sua efetivação.

Contudo, conforme o próprio relatório das Nações Unidas, o bem-estar e a vida digna envolvem muito mais do que o dinheiro, do que o capital. Falamos de acesso a bens materiais e imateriais, de uma vida a valorizar, com saúde, educação, identidade cultural, etc.

\section{Referências}

ALDUNATE, José (Org.). Direitos humanos, direitos dos pobres: desafios da vida na sociedade. São Paulo: Vozes, 1991. (Série V)

ARENDT, Hanna. A condição bumana. Rio de Janeiro: Forense Universitária, 2007.

ARRUDA JÚNIOR, Edmundo Lima de; GONÇALVES, Marcus Fabiano. Direito: ordem e desordem, eficácia dos direitos humanos e globalização. Florianópolis: IDA, 2004.

BACON, Francis. Novum Organum ou verdadeiras indicacões acerca da interpretação da natureza. Pará de Minas: M\&M, 2003.

BEOZZO, José Oscar. História da Igreja no Brasil II. Petrópolis: Cehila-Vozes, 1980. 
DUSSEL, Enrique. 1492: o encobrimento do outro (a origem do mito da modernidade). Petrópolis: Vozes, 1993.

FLEINER, Thomas. O que são direitos bumanos? São Paulo: Mas Limonad, 2003.

GROTIUS, Hugo. On the law of war and peace. Londres. 1814.

GROTIUS, Hugo. The freedom of the seas. New York: Oxford University Press, 1916.

HERRERA FLORES, Joaquín. Teoria crítica dos direitos humanos: os direitos humanos como produtos culturais. Rio de Janeiro: Lumen Juris, 2009.

KENNY, Charles. There's more to life than money: exploring the levels/growth paradox in health and education. Journal of international development, v. 21, n. 1, p. 24-41, 2009.

LAMY, Eduardo de Avelar; RODRIGUES, Horácio Wanderlei. Curso de processo civil: teoria geral do processo. Florianópolis: Conceito, 2010. v. 1.

LAS CASAS, Bartolomé de. Brevíssima relação da destruição das Índias: o paraíso destruído: a sangrenta história da conquista da América espanhola. Porto Alegre: L\&PM, 1991.

MIAILLE, Michel. Uma introdução crítica ao direito. Lisboa: Moraes, 1979.

NAÇÕES UNIDAS. Relatório de desenvolvimento bumano 2010: a verdadeira riqueza das nações: vias para o desenvolvimento humano. Disponível em: <http:// hdr.undp.org/en/media/HDR_2010_PT_Complete_ reprint.pdf $>$. Acesso em: 30 mar. 2011.
RODRIGUES, Horácio Wanderlei. O discurso dos direitos humanos como veículo da dominação exercida pelos países centrais. In. CAUBET, Christian Guy. (Org.). O Brasil e a dependência externa. São Paulo: Acadêmica, 1989. p. 35-56.

SÁNCHEZ VÁZQUEZ, Adolfo. Entre a realidade e a utopia: ensaios sobre política, moral e socialismo. Rio de Janeiro: Civilização Brasileira, 2001.

SARLET, Ingo Wolfgang. A eficácia dos direitos fundamentais: uma teoria geral dos direitos fundamentais na perspectiva constitucional. 10. ed. Porto Alegre: Livraria do Advogado, 2010.

SEN, Amartya. Poverty and Famines: an essay on Entitlement and Deprivation. Nova Iorque: Oxford University Press. 1983.

SMITH, Adam. A riqueza das nações: investigação sobre sua natureza e suas causas. São Paulo: Nova Cultura, 1996.

TODOROV, Tzvetan. A conquista da América: a questão do outro. 3. ed. São Paulo: Martins Fontes, 1993.

TRINDADE, Antonio Augusto Cançado. Tratado de direito internacional dos direitos humanos. Porto Alegre: Fabris, 1997. v. 1.

WILLIAMS, Raymond. El campo y la ciudad. Buenos Aires, Barcelona, México: Paidós, 2001. 
Para publicar na Revista de Direito Internacional, acesse o endereço eletrônico www.rdi.uniceub.br ou www.brazilianjournal.org.

Observe as normas de publicação, para facilitar e agilizar o trabalho de edição. 